\title{
Assessment of Right Ventricular Function in Post Operative Patients of Tetralogy of Fallots and Its Predictive Factors
}

\author{
Rana Sandeep Singh1, Rajat Kalra ${ }^{1 *}$, Rohit Manoj Kumar', Nidhi Rawal2, \\ Harkant Singh ${ }^{1}$, Reena Das ${ }^{3}$ \\ ${ }^{1}$ Department of Cardiothoracic Surgery, Postgraduate Institute of Medical Education and \\ Research, Chandigarh, India \\ ${ }^{2}$ Department of Cardiothoracic \& Cardiology, Postgraduate Institute of Medical Education and \\ Research, Chandigarh, India \\ ${ }^{3}$ Department of Hematopathology, Postgraduate Institute of Medical Education and Research, \\ Chandigarh, India \\ Email: rajat doc ucms@yahoo.co.in
}

Received 1 June 2014; revised 1 July 2014; accepted 1 August 2014

Copyright (C) 2014 by authors and Scientific Research Publishing Inc. This work is licensed under the Creative Commons Attribution International License (CC BY). http://creativecommons.org/licenses/by/4.0/

(c) (i) Open Access

\begin{abstract}
Introduction: Right ventricular (RV) dysfunction can occur early and late in patients after intracardiac repair (ICR) for Tetralogy of Fallots (TOF). This study focuses on early RV dysfunction as there is limited data on it. Aims \& Objective: RV function was studied with respect to its incidence, course over 3 months, co-relation with peri operative factors and serum iron levels. Material \& Method: All patients of TOF undergoing ICR during July 2007-October 2008, done by single surgeon at a single centre, were prospectively studied. Patients were divided into group A (with RV dysfunction) and group B (without RV dysfunction). All patients underwent pre operative \& post operative clinical assessment, biochemical evaluation (serum iron profile \& CK MB) and 2D echocardiography (pulse Doppler \& tissue Doppler). Echocardiography was done at 24 hours, 4 weeks $\& 12$ weeks of ICR. Patients were also assessed for intra operative parameters including cross clamp time, by pass time, acidosis, RV and PA pressures. Results: 24 patients underwent ICR (transannular patch repair) with mean age of $7.31 \pm 4.74$ years. RV dysfunction was present in 13 patients (54.2\%) but was persistent only in $15.3 \%(2 / 13)$ at 12 weeks. Presence of cyanotic spell (p $=0.006)$, recurrent chest infection $(p=0.002)$, raised heamatocrit $(p=0.02)$, and rise in serum iron level $(p=0.002)$ were significantly associated with post operative $R V$ dysfunction. It resulted in prolong ICU stay and slower recovery. Pre operative RV dysfunction was associated with diffi${ }^{*}$ Corresponding author.
\end{abstract}

How to cite this paper: Singh, R.S., Kalra, R., Kumar, R.M., Rawal, N., Singh, H. and Das, R. (2014) Assessment of Right Ventricular Function in Post Operative Patients of Tetralogy of Fallots and Its Predictive Factors. World Journal of Cardiovascular Surgery, 4, 139-150. http://dx.doi.org/10.4236/wjcs.2014.48021 
cult weaning from bypass and poor post operative outcome $(p<0.001)$. Conclusion: RV dysfunction is commonly present even after satisfactory ICR. Its aetiology remains unclear in such setting. In our study, pre operative clinical profile and serum iron fluctuations were important determinants of post operative outcome.

\section{Keywords}

Tetralogy of Fallot, Early RV Dysfunction, Predictive Factors

\section{Introduction}

Right Ventricular (RV) dysfunction can occur early \& late in patients after intracardiac repair (ICR) for Tetralogy of Fallot (TOF). This study focuses on early RV dysfunction as there is limited data on it [1]-[3].

\section{Aims and Objective}

RV function was studied with respect to its incidence \& course over 3 months, its co-relation with perioperative factors and serum iron levels. The usefulness of tissue doppler was evaluated for assessment of right ventricular function.

\section{Materials and Methods}

All patients of TOF undergoing ICR during July 2007-October 2008, operated by the same surgeon at a single centre, were prospectively studied. Pre operative clinical and demographic profile was noted for all patients.

\subsection{Pre Operative Measurements}

All patients underwent trans-thoracic echocardiography and tissue Doppler study within a week before surgery, in the immediate post operative period, 4 weeks and 12 weeks after intracardiac repair.

\subsubsection{D Echocardiography}

Transthoracic imaging was performed with the patient in the left lateral decubitus or supine position for the suprasternal views. Initially routine diagnostic imaging, including color flow mapping, and continuous-wave Doppler recordings were obtained. Pulsed Doppler recordings were made in each patient: 1 ) pulmonary arterial systolic and diastolic Doppler characteristics (the pulsed Doppler sample was placed at the midpoint between the pulmonary valve leaflets and bifurcation), 2) superior vena caval Doppler profile (1 to $2 \mathrm{~cm}$ proximal to the right atrium), 3) transtricuspid valve characteristics (at the level of the tips of the valve leaflets), E- and A-wave velocity/integral, and E-wave deceleration time.

\subsubsection{Tissue Doppler}

Tissue Doppler imaging (TDI) was used to measure the values of the peak tricuspid ring velocity during systole (Sa), early diastole (Ea), late diastole (Aa), isovolumetric contraction acceleration (IVA); isovolumetric contraction velocity (IVV), isovolumetric contraction time (ICT), isovolumetric relaxation time (IRT) of the RV. Tei index was calculated using the formula: (ICT + IRT)/Ejection Time (ET) [1]. Ea/Aa ratio, E wave deceleration time (Edt) were also noted.

\subsubsection{Definition of RV Dysfunction}

Tissue Doppler:

We can measure both systolic \& diastolic myocardial velocities using tissue Doppler. Systolic dysfunction was present if there was decrease in Sa, IVA, IVV at free wall of RV [2] [3]. Diastolic dysfunction was present when $\mathrm{A}>\mathrm{E}, \mathrm{E} / \mathrm{A}<1$ or there was a decrease in Edt [3] [4]. Tei index was measure to assess global RV function [1] [3].

Flow Doppler:

Diastolic dysfunction was present when there was presence of an antegrade diastolic pulmonary flow coin- 
ciding with atrial systole [5] [6].

\subsection{Operative Technique}

Informed consent was taken from all patients. All operations were performed under standard cardiopulmonary bypass through median sternotomy. Aorto-bicaval cannulation was performed and patient put on cardiopulmonary by pass. Aorta was cross clamped; all patients were cooled to $28^{\circ} \mathrm{C}$. Cold blood cardioplegia was given in aortic root to arrest the heart. The procedure was performed through right atrium in all cases. Adequate infundibular resection was performed. VSD was closed using PTFE patch sutured in place with interrupted prolene sutures. Main pulmonary artery, pulmonary annulus and RVOT were augmented by applying a pericardial patch wherever required.

\section{Intra Operative Measurements}

Aortic cross clamp time, Cardiopulmonary bypass time, mean $\mathrm{pH}$ \& base deficit during bypass were recorded. Pressures were measured in RV and PA after coming off the cardio pulmonary bypass.

\subsection{Post Operative Measurements}

All patients in post operative period were assessed through recovery parameters (ventilator dependence, ICU stay, chest drain Time, inotrope duration, diuretic requirement).

\section{Biochemical Parameters}

Serum iron profile (serum iron, total iron binding capacity, percentage transferrin saturation, ferritin levels) were measured pre operatively \& within 24 hours of ICR. Serum Iron studies were calculated based on revised recommendation for the measurement of serum iron in human blood [7]. Creatinine phosphokinase isoenzyme type MB (CK MB) was measured in post operative period as an indirect measure of myocardial injury.

\section{Statistics}

The pre operative, intra operative and post operative measured parameters were recorded in the proforma $\&$ their relation to post operative RV dysfunction was analyzed statistically by using standard statistical methods. Student " $t$ " test was used for normaly distributed continuous variables. For skewed data, non parametric test (Mann Whitney U/Wilcoxon) was used for analyzing continuous variables. Chi squre test was used for analysis of categorical variables. All results were expressed as mean \pm standard deviation.

\section{Results}

24 patients were taken up for ICR for correction of TOF between Jul 2008-Oct 2009. 13 patients had evidence of $\mathrm{RV}$ dysfunction in immediate post operative period. The mean age of patients was $7.31 \pm 4.74$ years (2.5 years - 19 years). There were 19 males (79.16\%) and 5 females (20.83\%). There were no significant differences in demographic profile of patients developing RV dysfunction in post operative period as compared to those with normal RV function (Table 1).

The most common clinical feature in patients of TOF was dyspnea on exertion (DOE). It was present in 95.8\% (23/24) patients. The prognostic significance of clinical features at presentation to post operative RV function were correlated (Table 2). It was found that history of recurrent cyanotic spells \& recurrent Lower Respiratory Tract Infection (LRTI) correlated with poor post operative function irrespective of duration of cyanosis \& DOE. Another important observation was that patients developing RV dysfunction had significantly higher pre operative hemoglobin as compared to those with no RV dysfunction (Table 2).

Table 1. Demographic profile of patients \& its relation to RV function.

\begin{tabular}{cccc} 
& Values $(\mathrm{N}=24)$ & RV dysfunction $(\mathrm{N}=13)$ & No RV dysfunction $(\mathrm{N}=11)$ \\
\hline Mean age $(\mathrm{y})$ & $7.31 \pm 4.74$ & $5.92 \pm 3.94$ & $8.95 \pm 5.25$ \\
Sex profile $(\mathrm{M} / \mathrm{F})$ & $19 / 5$ & $9 / 4$ & $10 / 1$ \\
BSA $\left(\mathrm{m}^{2}\right)$ & $0.77 \pm 0.32$ & $0.66 \pm 0.19$ & 0.12 \\
\hline
\end{tabular}




\section{Intra operative factors \& their bearing on post operative RV function:}

It was found that ACC, CPB time, duration of surgery were not significantly different in patient with RV dysfunction as compared to those without RV dysfunction (Table 3).

\section{Other associated anomalies:}

Two patients had a right sided aortic arch (8.3\%) and 2 patients had a left sided persistent SVC draining into the coronary sinus $(8.3 \%)$. There was no impact of associated anomalies on post operative RV function $(\mathrm{p}=$ $0.06)$.

\section{Post operative indicator of RV dysfunction:}

Thirteen (54.2\%) patients had echocardiographic features suggestive of RV dysfunction in post operative period.

Clinical indicator of RV dysfunction:

Patient developing significant RV dysfunction required more ventilation hours \& longer inotropic support. As a result the ICU stay of these patients was also longer as compared to those with no deterioration of RV function (Table 4).

Biochemical indicator of RV dysfunction:

Pre operative iron profile was comparable in both the groups. In the post operative period, patients developing RV dysfunction had higher serum iron and transferrin saturation. However, they had a lower transferrin iron binding capacity (TIBC) as compared to those with no evidence of RV dysfunction in post operative period. It was also evident that myocardial injury (stress/surgery induced) was more in patients developing RV dysfunction as indicated by raised serum CK MB levels, as compared to those with no evidence of RV dysfunction in post operative period (Table 5).

There was a significant difference in pre operative \& post operative serum iron, transferrin saturation and TIBC in patients developing RV dysfunction as compared to patients without RV dysfunction (Table 6).

Table 2. Implication of clinical features on post operative RV function.

\begin{tabular}{cccc}
\hline & RV dysfunction $(\mathrm{N}=13)$ & No RV dysfunction (N = 11) & p value \\
\hline Duration of cyanosis (months) & $47 \pm 46.67$ & $68.54 \pm 62$ & 0.34 \\
Duration of DOE (months) & $31.3 \pm 22.83$ & $48.54 \pm 51.50$ & 0.51 \\
Cyanotic spells & 11 & 3 & 0.006 \\
Palpitation & 11 & 9 & 0.03 \\
Recurrent LRTI & 8 & 0 & 0.02 \\
Pre operative Hb (gm\%) & $18.31 \pm 2.85$ & $15.68 \pm 2.41$ & 0.02 \\
\hline
\end{tabular}

Table 3. Intra operative factors \& their relation to post operative RV function.

\begin{tabular}{|c|c|c|c|c|}
\hline Parameter & Mean $(\mathrm{N}=24)$ & RV dysfunction $(\mathrm{N}=13)$ & No RV dysfunction $(\mathrm{N}=11)$ & $\mathrm{p}$ values \\
\hline Pre operative phlebotomy (n) & 1 & 0 & 1 & 0.45 \\
\hline ACC time (min) & $128.62 \pm 26.56$ & $129.53 \pm 31.15$ & $127.54 \pm 21.35$ & 0.85 \\
\hline CPB Time (min) & $192.62 \pm 49.17$ & $200.07 \pm 63.15$ & $183.81 \pm 24.86$ & 0.97 \\
\hline RV pressure (mmHg) & $54.62 \pm 8.97$ & $53 \pm 10.84$ & $56.54 \pm 6.03$ & 0.13 \\
\hline MPA pressure (mmHg) & $39 \pm 9.75$ & $37.38 \pm 12.28$ & $40.90 \pm 5.50$ & 0.10 \\
\hline
\end{tabular}


Table 4. Post operative indicators of RV dysfunction.

\begin{tabular}{ccccc}
\hline Parameter & Mean (N = 24) & RV dysfunction (N=13) & No RV dysfunction (N = 11) & p values \\
\hline Ventilation (h) & $33.50 \pm 28.05$ & $46.92 \pm 32.63$ & $17.63 \pm 4.54$ & 0.002 \\
Drain time (h) & $104.12 \pm 93.29$ & $122.76 \pm 112$ & $82.09 \pm 62.76$ & 0.29 \\
Inotrope duration (h) & $53.04 \pm 34.97$ & $66.30 \pm 40.23$ & $35.80 \pm 15.76$ & 0.03 \\
ICU stay (days) & $3.79 \pm 1.71$ & $4.38 \pm 2.18$ & $3.09 \pm 0.36$ & 0.05 \\
\hline
\end{tabular}

Table 5. Post operative biochemical profile.

\begin{tabular}{|c|c|c|c|c|}
\hline Parameter & Mean N = 24 & RV dysfunction $\mathrm{N}=13$ & No RV dysfunction $\mathrm{N}=11$ & $\mathrm{p}$ value \\
\hline Serum iron $(\mu \mathrm{g} / \mathrm{dl})$ & $74.25 \pm 36.42$ & $92.62 \pm 39.93$ & $52.55 \pm 13.48$ & 0.004 \\
\hline Serum TIBC $(\mu \mathrm{g} / \mathrm{dl})$ & $379.13 \pm 74.88$ & $342.45 \pm 71.32$ & $422.45 \pm 55.99$ & 0.006 \\
\hline$\%$ Transferrin saturation & $21.63 \pm 14.16$ & $29.28 \pm 15.41$ & $12.59 \pm 3.19$ & 0.002 \\
\hline Serum ferritin $(\mu \mathrm{g} / \mathrm{l})$ & $71.04 \pm 60.01$ & $80.54 \pm 60.42$ & $59.82 \pm 60.36$ & 0.41 \\
\hline CPK-MB & $82.05 \pm 29.14$ & $94.19 \pm 30.15$ & $67.70 \pm 21.07$ & 0.002 \\
\hline
\end{tabular}

Table 6. Changes $(\Delta)$ in iron profile predicting RV dysfunction.

\begin{tabular}{ccccc}
\hline Parameter & Mean N = 24 & RV dysfunction $\mathrm{N}=13$ & No RV dysfunction $\mathrm{N}=11$ & $\mathrm{p}$ value \\
\hline$\Delta$ Serum iron $(\mu \mathrm{g} / \mathrm{dl})$ & $29.54 \pm 29.73$ & $45.46 \pm 31.64$ & $10.12 \pm 10.65$ & 0.002 \\
$\Delta$ Serum TIBC $(\mu \mathrm{g} / \mathrm{dl})$ & $77.75 \pm 61.88$ & $100.62 \pm 72.01$ & $50.72 \pm 33.24$ & 0.046 \\
$\Delta \%$ Transferrin saturation & $11.66 \pm 12.21$ & $18.44 \pm 13.15$ & $3.63 \pm 2.17$ & 0.002 \\
& & & $41.81 \pm 55.89$ & 0.43 \\
\hline
\end{tabular}

\section{Echocardiographic assessment of RV function:}

13 patients showed features of RV dysfunction on tissue Doppler analysis. Presence of diastolic dysfunction was evident as $\mathrm{Aa}>\mathrm{Ea}, \mathrm{Ea} / \mathrm{Aa}<1$, shorter deceleration time. Presence of significantly less ICT in patients with RV dysfunction can be explained due to inadequate diastolic relaxation before onset of systole (Table 7 \& Table 8 ).

RV function assessment on follow up is shown with help of graphs below:

After undergoing ICR 11/24 patients on tissue Doppler showed improvement in Aa, ICT, Edt, Tei index, which continued even at the end of 12 weeks (patients without RV dysfunction). 13/24 patients showed worsening of these indices immediately following ICR but this subset also showed improvement at the end of 12 weeks (Figures 1-4).

There were 13 (54.16\%) patients who had features of right ventricular dysfunction on echocardiography in the immediate post operative period. At 4 weeks 5/13 (38.46\%) patients with immediate RV restrictive physiology continued to show persistent RV diastolic dysfunction. At 12 weeks, of the 13 patients with immediate RV restrictive physiology who were studied, 3 more patients showed disappearance of antegrade PA diastolic flow along with tissue Doppler anomalies. Also, 2 (15.38\%) patients continued to show persistent abnormalities despite significant clinical improvement (Figure 5). 
Table 7. Tissue Doppler analysis of RV function in post op period.

\begin{tabular}{cccc}
\hline Tissue Doppler & RV dysfunction $(\mathrm{N}=13)$ & No RV dysfunction $(\mathrm{N}=11)$ & p value \\
\hline Sa $(\mathrm{cm} / \mathrm{sec})$ & $10.60 \pm 3.33$ & $10.11 \pm 2.60$ & 0.70 \\
Ea (cm/sec) & $12.24 \pm 3.43$ & $13.53 \pm 4.09$ & 0.77 \\
Aa $(\mathrm{cm} / \mathrm{sec})$ & $14.48 \pm 4.72$ & $10.09 \pm 3.90$ & 0.02 \\
E/A & $0.91 \pm 0.45$ & $1.40 \pm 0.37$ & 0.009 \\
E wave deceleration time (msec) & $62.15 \pm 19.32$ & $86.18 \pm 23.86$ & 0.01 \\
IRT (msec) & $38.53 \pm 16.29$ & $44 \pm 14.71$ & 0.40 \\
ICT (msec) & $50.92 \pm 15.31$ & $67.18 \pm 20.16$ & 0.03 \\
Tei INDEX & $0.44 \pm 0.11$ & $0.47 \pm 0.095$ & 0.38 \\
IVV (cm/sec) & $8 \pm 2.99$ & $7.45 \pm 2.31$ & 0.62 \\
IVA (m/sec $\left.{ }^{2}\right)$ & $2.73 \pm 1.18$ & $3.05 \pm 1.36$ & 0.55 \\
\hline
\end{tabular}

Table 8. RV function on 2D pulse Doppler in immediate post operative period.

\begin{tabular}{ccc}
\hline & RV dysfunction $(\mathrm{N}=13)$ & No RV dysfunction $(\mathrm{N}=11)$ \\
E (cm/sec) & $70.73 \pm 14.94$ & $80.32 \pm 20.01$ \\
A (cm/sec) & $64.23 \pm 28.98$ & $64.24 \pm 17.73$ \\
E/A & $1.24 \pm 0.77$ & $1.27 \pm 0.24$ \\
E wave deceleration time (msec) & $73.23 \pm 26.10$ & $111.36 \pm 23.23$ \\
IRT (msec) & $37.84 \pm 12.12$ & $47.36 \pm 11.99$ \\
ICT (msec) & $46.15 \pm 25.73$ & 0.001 \\
Tei INDEX & $0.36 \pm 0.13$ & 0.06 \\
\hline
\end{tabular}

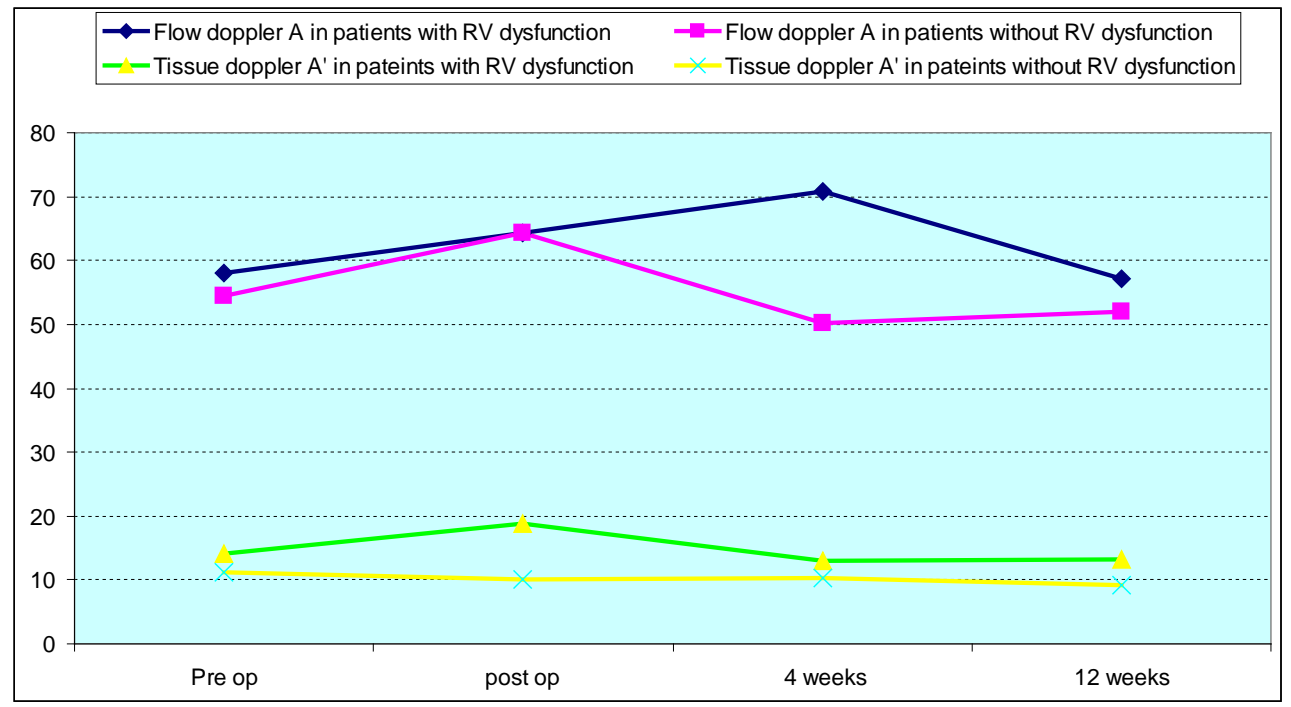

Figure 1. Late diastolic velocity trend on tissue (A') \& pulse Doppler (A) echocardiography. Flow Doppler: At 4 weeks p between groups $=0.08$; Tissue Doppler: in post operative period p between the groups $=0.02$; Trend in pt without RV dysfunction: p (pre vs. $12 \mathrm{wks}$ ): 0.052 . 


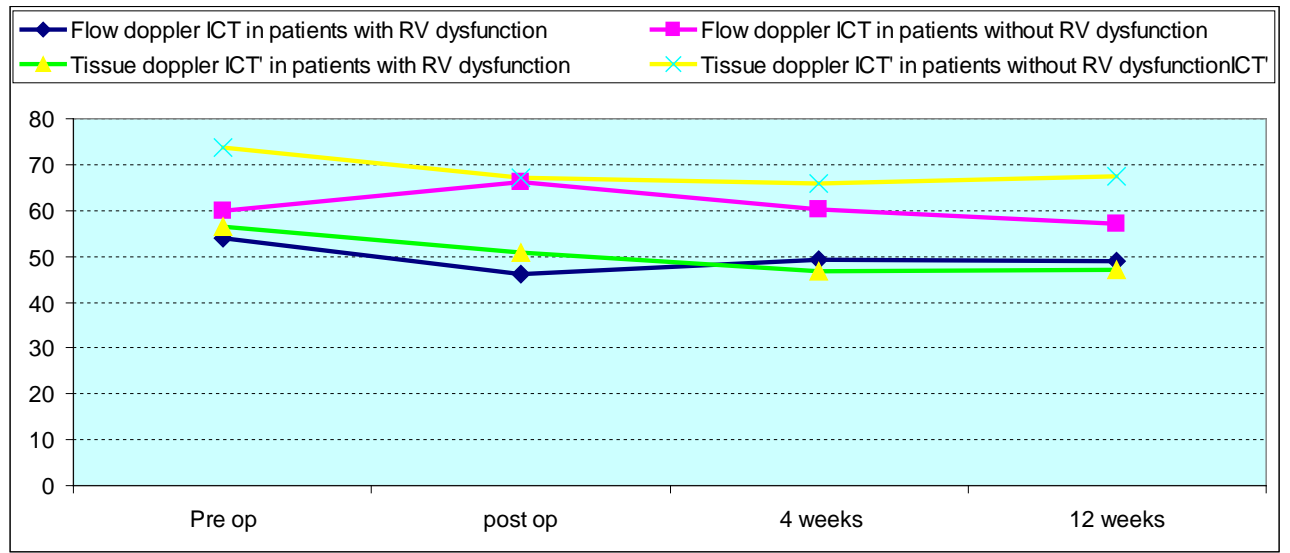

Figure 2. Tissue Doppler \& flow Doppler ICT in patients with \& without RV dysfunction. Tissue Doppler: pre op p value between groups: 0.05 ; Post operative period $\mathrm{p}$ between the groups $=0.03$; At 4 wks p value between gps $=0.02 ; 12$ wks p value between groups: 0.02 .

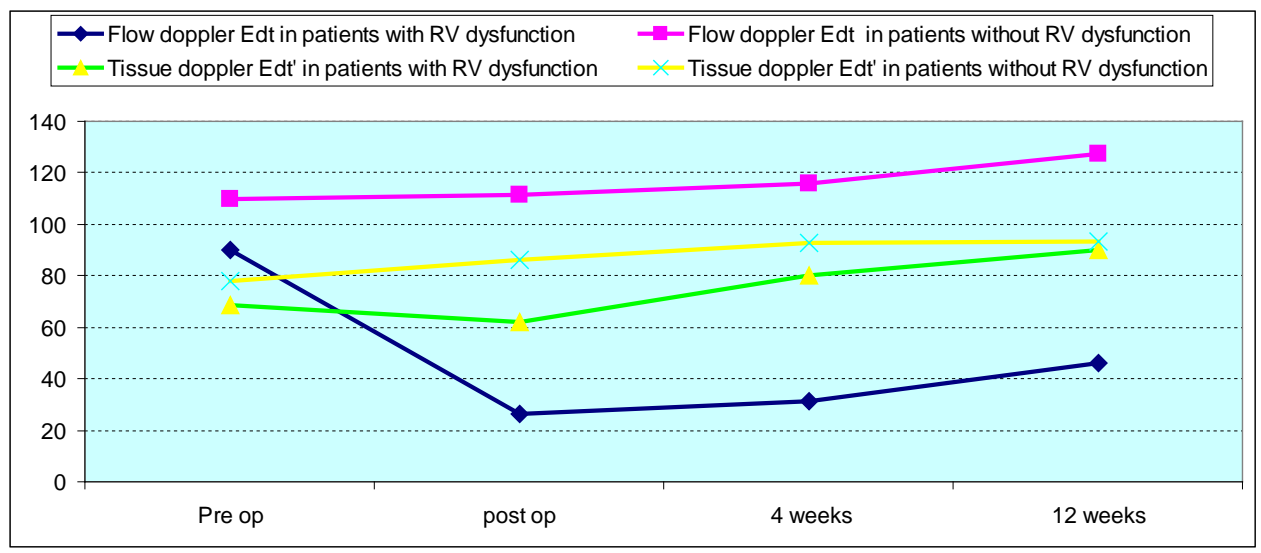

Figure 3. Tissue Doppler \& pulse Doppler Edt \& its variation in patients with RV dysfunction. Flow Doppler: trends in patient with RV dysfunction: p (pre vs. post): 0.049; p (post vs. 4 wks): 0.01; Tissue Doppler: trend in patient with RV dysfunction: p (post vs. 4 wks): 0.005 .

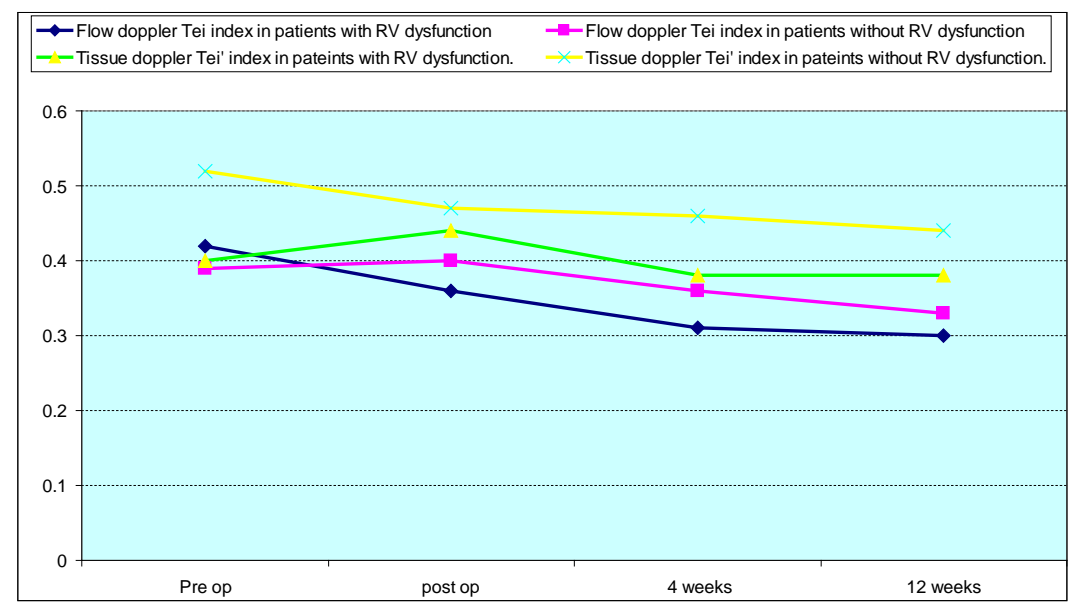

Figure 4. Pulse Doppler \& tissue Doppler derived tei index trend over 12 weeks. Flow Doppler: Trend in patient without RV dysfunction: p (post op vs. 4 wks): 0.005; p (4 wks vs. 12 wks): 0.007; Tissue Doppler: trend in patients without RV dysfunction: p (pre vs. post): 0.04; p (4 wks - 12 wks): 0.003 . 


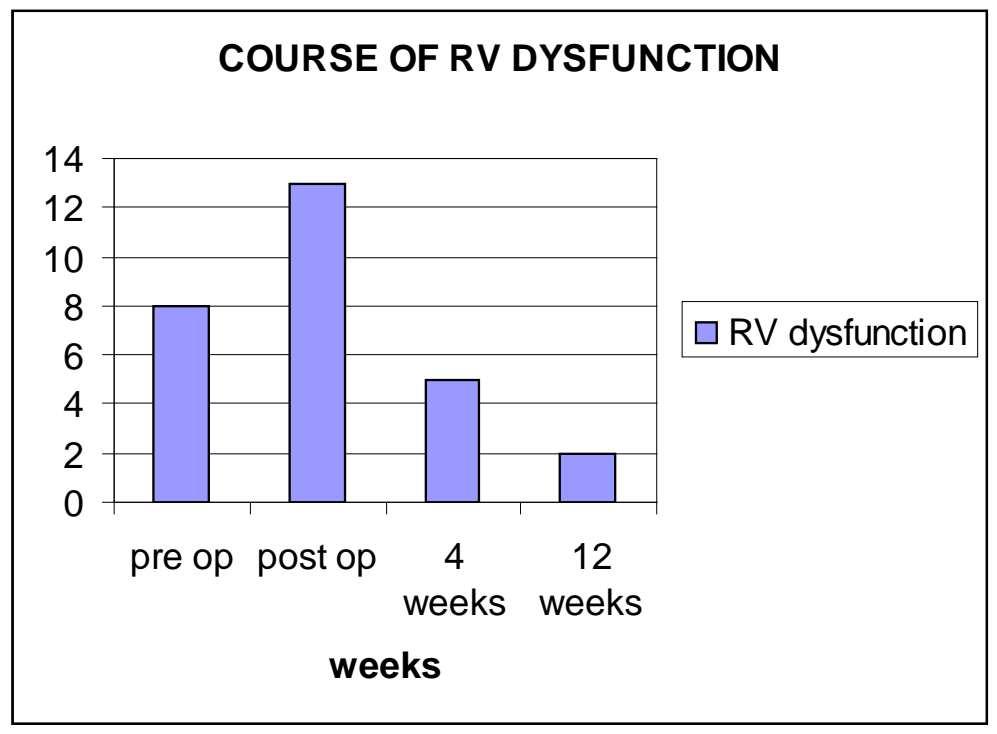

Figure 5. Course of RV dysfunction.

\section{Discussion}

Intra cardiac repair is the definitive management of TOF. Refinement in surgical techniques, advancements in anaesthetic \& critical care has resulted in improving survival following ICR. Post operative mortality following ICR is reported between $1 \%-5 \%$ [8]. Post operative low cardiac output and mortality has been attributed to many factors such as anatomical defects with small main pulmonary artery annulus, severe hypoplasia or absent right or left pulmonary artery, ventriculotomy and right ventricular (RV) outflow patch, myocardial hypoxia during cardiopulmonary bypass, or ARDS [9]. Certain patients despite satisfactory ICR exhibit difficult post operative course which is characterised by prolonged ventilation $\&$ inotropic support. These patients have been identified to exhibit features of RV dysfunction (low cardiac output, high central venous filling pressure, increased inotropic requirement, and prolonged ventilation). Identification of risk factors to characterise this subset of patients allows for better allocation of hospital resources, improved outcome, and substantially reduced hospital costs.

We have tried to identify the risk factors associated with development of RV dysfunction \& its course over a period of three months in patients of tetralogy following ICR.

\section{Incidence of RV dysfunction:}

It has been shown that RV dysfunction in the immediate post operative period is characterized by features of restrictive physiology on Doppler echocardiography (presence of an antegrade diastolic pulmonary flow coinciding with atrial systole) [5] [6]. Its prevalence in the literature ranges from $28 \%$ to $63 \%$ [3]-[6] [10]. In our study, with an intermediate post operative follow-up of 3 months, $54.16 \%$ of the patients had RV dysfunction (restrictive physiology) immediately following ICR. The high incidence in our study can be explained due to the following reasons:

- The use of a transannular patch, in all patients, in the study: It has been seen that there is a correlation between this technique and the appearance of anterograde diastolic flow in the pulmonary artery [9] [11].

- Use of tissue Doppler (along with 2D pulse Doppler) to assess RV function which is more sensitive than 2D pulse Doppler [1]-[3] [12].

\section{Pre operative factors \& their relationship to RV dysfunction:}

Demographic profile of patients developing RV dysfunction:

Age:

Repair at early age has been shown to reduce post operative RV dysfunction due to chronic hypoxia and pressure loading, which leads to formation of substrate in myocardium that is responsible for arrhythmias and diastolic dysfunction in patients undergoing late repair [13]. It has been seen that significant RV remodeling occurs if repair is carried before 6 months of age [14]. It has been proposed on basis of microscopic examination that irreversible changes set in by 4 years of age, therefore it is best to carry repair before 3 years of age [15]. The above mentioned studies suggest that repair carried out before 3 years of age may lead to regression of myo- 
cardial changes but best functional outcome being achieved before 1 year of age when changes are just beginning to set in. In our study the mean age of patients with RV dysfunction was 5.92 years as compared to 8.95 years in patients without RV dysfunction (Table 1). This paradox is similar to that reported in other studies [4] [6] [10]. Therefore beyond 3 year age, background of irreversible changes, “age” may have decreasing influence on post operative outcomes.

Clinical features \& RV dysfunction:

The relationship of clinical features was studied with respect to post operative course.

Influence of cyanosis \& its severity on RV function:

83.3\% (20/24) of patients were cyanotic while $16.7 \%(4 / 24)$ were acyanotic at admission. It has been seen in various studies that cyanosis has detrimental effect on myocardium, its metabolism \& surgical outcome [16] [17]. This can also be seen from our study, that patients with RV dysfunction in post operative period were more cyanotic as their mean haematocrit was significantly more as compared to patients with no RV deterioration (57.60 vs. 47.04; $\mathrm{p}=0.02$ ).

On the other hand cyanosis itself is not the only determinant of post operative RV dysfunction as $50 \%$ of acyanotic patient (2/4) also had RV dysfunction in the post operative period.

Cyanotic spells:

Cyanotic spell has been related with post operative ventricular dysfunction in some studies [18] [19]. Lorgeril et al. found cyanotic spell in $46 \%$ of patients \& found its significant impact on the left ventricular function 19 , while in our study it was found in $58.3 \%$ of patients \& was significantly associated with post operative RV dysfunction.

Pre operative hemoglobin:

Morbidity \& mortality following ICR is directly related to the severity of the disease (TOF) being treated. A haemoglobin level more than 18 has been associated with severe disease in literature [19]. In our study also patients with post operative RV dysfunction had mean $\mathrm{Hb}$ of $18.31 \mathrm{gm} \%$ as compared to $15.68 \mathrm{gm} \%$ in patients without RV dysfunction thereby signifying presence of severe disease in the former group.

Recurrent LRTI:

Cobanoglu et al. observed relatively high mortality following ICR in patients of TOF with recurrent respiratory tract infection in their study [20]. They related this to poor pulmonary function as a result of frequent infections. They did not correlate it with myocardial function. The association between restrictive physiology \& recurrent respiratory tract infection has not been reported. It was observed in our study that patients with prolonged post operative course, had history of recurrent lower respiratory tract infections as compared to patients with normal post operative course. The association was statistically significant. The exact mechanism responsible for poor post operative RV function \& its outcome still remains to be elucidated. We believe that recurrent hypoxia \& re oxygenation leads to production of free radicals in pulmonary circulation. These free radicals on reaching the heart causes damage of predisposed myocardium which is not well equipped to deal with oxidative stress in setting of TOF [21]. The detrimental effect of cyanotic spell (precipitated by these infection) on myocardium may also be a cause of the RV dysfunction as discussed earlier. Further study, investigating the relationship of respiratory tract infection symptoms and its functional impact on outcomes after repair of TOF, may be interesting to pursue.

Intra operative factors \& relation to post operative RV function:

All patients underwent transannular patch repair. Therefore impact of type of surgery to post operative RV function cannot be commented upon in this study.

There was no significant difference in ACC, CPB time and total duration of surgery in patients with and without RV dysfunction (Table 4). Similar results were also given in other studies [4]-[6] [10] on post operative RV dysfunction.

\section{Complication:}

There were 3 mortalities in the post operative period. Two patients had severe cyanosis on admission, with arterial saturation between 65\% - 79\%. All three patients had evidence of diastolic dysfunction on pre operative echocardiography. These patients had difficulty in weaning from bypass \& required heavy inotropic support while coming off bypass. All of them had low output syndrome \& showed evidence of persistent diastolic dysfunction in the post operative period. 2 patients expired after 24 hours while the third patient expired after 48 hours of advanced critical care. During surgery, one of these patients was required to be taken back on CPB due to high RV pressure as a result of residual RVOT obstruction (repair was revised). 
There was another patient who was required to be put back on CPB for residual RVOT obstruction resulting in high RV pressure. This patient developed RV dysfunction and recovered with help of longer ventilatory and inotropic support.

\section{Biochemical indicator of RV dysfunction:}

In the only study of its kind Chaturvedi et al. [22] found that restrictive dysfunction in post operative period was associated with greater intra operative myocardial injury and post operative oxidative stress with severe iron loading of transferrin. They had shown a positive correlation between iron concentration, trop T level \& post operative RV dysfunction. We did iron profile in all patients of this study and found that there was a decrease in TIBC, increased serum iron levels, increased transferrin saturation, and increases CK MB levels in patients developing RV dysfunction following the repair (Table 5).

The acute-phase response of systemic inflammation due to cardiopulmonary bypass includes a fall in total iron-binding capacity and transferrin that has been attributed to extravasations of these proteins [23]. A pattern of iron overload (bypass related haemolysis, mobilization of tissue iron into the vascular compartment after ischemia, and cardiomyocyte necrosis liberating myoglobin and other intracellular proteins containing iron) superimposed on this acute-phase response result in increase in availability of free iron which acts as catalyst for free radical production [24] [25]. The decrease in TIBC along with increase in serum iron results increase in availability of free iron even though mean levels of serum iron approached high normal values in our study. Ferritin is acute phase reactant protein, whose levels increases during inflammation [26]. The uniform inflammatory response to stress of cardiopulmonary bypass may explain significant rise of ferritin in both the groups despite iron overloading in patient with RV dysfunction only. Therefore there was no statistical significant difference in mean serum ferritin levels in patients with \& without RV dysfunction in post operative period $(p=0.41)$. TOF myocardium has diminished antioxidant defences and is vulnerable to free radical-mediated injury [21]. Therefore free radical induced myocardial damage may also contribute to impaired RV function.

The CK MB levels were significantly raised in patients developing post operative RV dysfunction (Table 5). This indicates that myocardial damage in patients following ICR was significantly more in patient with RV dysfunction as compared to patients in the normal post operative course.

Thus patients destined to develop acute RV diastolic dysfunction with restrictive physiology, suffer more intrao perative myocardial injury and subsequent oxidative stress which may be related to increased iron concentrations.

Assessment of RV function: Tissue Doppler vs. flow/pulse Doppler:

MRI is a gold standard for assessment of right ventricular function [27]. However, MRI has restricted availability, is costly, and there are many patients in whom MRI-non compatible devices prohibit its use. It has been shown, that on principle tissue Doppler is more sensitive than pulse/flow Doppler as it measures myocardial velocities rather than flow dynamics [1]-[3]. Its usefulness in the assessment of ventricular function, with and without heart diseases, has recently been reported [1]-[3]. Systolic annular velocity (Sa), isovolumic velocity (IVV), isovolumic acclerration (IVA) have been shown to be measure of systolic function [1]-[3] whereas early diastolic velocity (Ea), late diastolic velocity (Aa), Ea/Aa ratio \& E wave deceleration time (Edt) are measure of diastolic function [3] [4]. In our study flow Doppler analysis confirmed the presence of antegrade diastolic flow in all 13 patients showing dysfunction on tissue Doppler. Pulse Doppler analysis did not depict evident diastolic dysfunction seen on tissue Doppler except for decrease in Edt in all these 13 patients. Tissue Doppler, being more objective method than depiction of antegrade diastolic flow on flow Doppler (require experience), is likely to become preferred modality for RV assessment.

Prognostic value of pre op RV dysfunction:

Restrictive RV physiology can occur both early and late after repair [5] [28]. It is not known whether this is the same phenomenon and whether the same anatomical substrate is involved. Diastolic dysfunction may indicate more ischemic myocardium and thus greater extent of muscle susceptible to reperfusion injury or ischemic insult. Denault et al. have shown in their study in adult patients that diastolic dysfunction is predictive of difficult weaning from Cardiopulmonary Bypass [29]. In our study 8 of the patients had echocardiographic finding suggestive of diastolic dysfunction pre operatively. All of these 8 patient required increased inotrope while coming off bypass, as against the other 16 patients $(4 \pm 0.92$ vs. $2.62 \pm 0.62 \mathrm{p}=0.001)$. There were 3 mortalities in immediate post operative period. All of three patients demonstrated pre operative RV dysfunction

Course of RV function:

There were 13 (54.16\%) patients who had features of right ventricular dysfunction on echocardiography in 
immediate post operative period. At 4 weeks 5/13 (38.46\%) patients with immediate RV restrictive physiology continued to show persistent RV diastolic dysfunction. Of these 5 patients, 4 were in modified ross [30] class II while 1 was in class III. All patients without RV restriction were in modified ross class I. At 12 weeks, only 2 (15.38\%) patients continued to show persistent abnormalities despite significant clinical improvement. There was no patient developing RV dysfunction following normal post operative course (absent RV restriction following ICR and developing it on the follow-up echocardiographic study). Hence transient restrictive physiology seen following ICR, resolved in $61 \%$ (8/13) of cases by 12 weeks whereas in $15.38 \%$ (2/13) of cases it persisted. 3 mortalities in immediate post operative period were excluded from follow up analysis at 4 weeks. The incidence of early RV dysfunction has been reported between $28 \%$ - 63\% in various studies [3]-[6] [10]. It is possible that the widely different age groups of the patient populations in the different studies are responsible for these discrepancies in observation.

\section{Clinical implication:}

The right ventricular dysfunction developing following ICR is responsible for slow post operative course \& prolongs recovery. Pre operative right ventricular diastolic dysfunction could represent an additional marker to identify populations at higher risk of requiring vasoactive support and potentially adverse clinical outcomes of difficult weaning from by pass $\&$ increase post operative mortality.

\section{Conclusions}

1) RV dysfunction is commonly present even after satisfactory ICR. It is transient and resolves in maximum number of patients over 12 weeks.

2) Its aetiology remains unclear in such setting. In our study pre operative clinical profile, VSD size, and serum iron fluctuations were important determinants of post operative outcome.

3) Tissue Doppler is a sensitive means to assess RV function.

\section{Limitation of Study}

1) Relatively small sample size.

2) Intermediate follow-up of 3 months.

\section{References}

[1] Yasuoka, K., Harada, K., Toyono, M., Tamura, M. and Yamamoto, F. (2004) Tei Index Determined by Tissue Doppler Imaging in Patients with Pulmonary Regurgitation After Repair of Tetralogy of Fallot. Pediatric Cardiology, 25, 131136. http://dx.doi.org/10.1007/s00246-003-0514-3

[2] Toyono, M., Harada, K., Tamura, M., Yamamoto, F. and Takada, G. (2004) Myocardial Acceleration during Isovolumic Contraction as a New Index of Right Ventricular Contractile Function and Its Relation to Pulmonary Regurgitation in Patients after Repair of Tetralogy of Fallot. Journal of the American Society of Echocardiography, 17, 332337. http://dx.doi.org/10.1016/j.echo.2003.12.022

[3] Harada, K., Toyono, M. and Yamamoto, F. (2004) Assessment of Right Ventricular Function during Exercise with Quantitative Doppler Tissue Imaging in Children Late after Repair of Tetralogy of Fallot. Journal of the American Society of Echocardiography, 17, 863-869. http://dx.doi.org/10.1016/j.echo.2004.04.037

[4] Cardoso, S.M. and Miyague, N.I. (2003) Right Ventricular Diastolic Dysfunction in the Postoperative Period of Tetralogy of Fallot. Arquivos Brasileiros de Cardiologia, 80, 198-201. http://dx.doi.org/10.1590/S0066-782X2003000200008

[5] Cullen, S., Shore, D., Redington, A., et al. (1995) Characterization of Right Ventricular Diastolic Performance after Complete Repair of TOF: Restrictive Physiology Predicts Slow Post Operative Recovery. Circulation, 91, 1782-1789. http://dx.doi.org/10.1161/01.CIR.91.6.1782

[6] Sachdev, M.S., Bhagyavathy, A., Varghese, R., et al. (1999) Right Ventricular Diastolic Function after Repair of Tetralogy of Fallot. Paediatric Cardiology, 9, 384-391.

[7] (1990) Revised Recommendation for the Measurement of Serum Iron in Human Blood. British Journal of Haematology, 75, 615-616. http://dx.doi.org/10.1111/j.1365-2141.1990.tb07808.x

[8] Kirklin, J.W. and Barrat-Boyes, B.G. (1993) Ventricular Septal Defect and Pulmonary Stenosis or Atresia. In: Cardiac Surgery, 2nd Edition, Vol. 2, Churchill Livingstone Inc., New York, 919.

[9] Eroglu, A.G., Sarioglu, A., Sarioglu, T., et al. (1999) Right Ventricular Diastolic Function after Repair of Tetralogy of Fallot: Its Relationship to the Insertion of a "Transannular” Patch. Cardiology in the Young, 9, 384-391. 
[10] Rathore, K.S., Gupta, N., Kapoor, A., et al. (2004) Assessment of Right Ventricular Diastolic Function: Does It Predict Post Operative Course in Tetralogy of Fallot. Indian Heart Journal, 56, 220-224.

[11] Norgård, G., Gatzoulis, M.A., Moraes, F., Lincoln, C., Shore, D.F., Shinebourne, E.A. and Redington, A.N. (1996) Relationship between Type of Outflow Tract Repair and Postoperative Right Ventricular Diastolic Physiology in Tetralogy of Fallot. Implications for Long-Term Outcome. Circulation, 94, 3276-3280. http://dx.doi.org/10.1161/01.CIR.94.12.3276

[12] Galderisi, M., Severino, S., Cicala, S. and Caso, P. (2004) The Usefulness of Pulsed Tissue Doppler for the Clinical Assessment of Right Ventricular Function. Italian Heart Journal, 3, 241-247.

[13] Munkhammar, P., Cullen, S., Jögi, P., de Leval, M., Elliott, M. and Norgård, G. (1998) Early Age at Repair Prevents Restrictive Right Ventricular (RV) Physiology after Surgery for Tetralogy of Fallot (TOF): Diastolic RV Function after TOF Repair in Infancy. Journal of the American College of Cardiology, 32, 1083-1087. http://dx.doi.org/10.1016/S0735-1097(98)00351-9

[14] Seliem, M.A., Wu, Y.T. and Glenwright, K. (1995) Relation between Age at Surgery and Regression of Right Ventricular Hypertrophy in Tetralogy of Fallot. Pediatric Cardiology, 16, 53-55. http://dx.doi.org/10.1007/BF00796817

[15] Kato, M. (1976) Right Ventricular Hypertrophy in Tetralogy of Fallot; Pathohistologic Study. Japanese Association for Thoracic Surgery, 25, 1436-1445

[16] Najm, H.K., Wallen, W.J., Belanger, M.P., Williams, W.G., Coles, J.G., Van Arsdell, G.S., et al. (2000) Does the Degree of Cyanosis Affect Myocardial Adenosine Triphosphate Levels and Function in Children Undergoing Surgical Procedures for Congenital Heart Disease? The Journal of Thoracic and Cardiovascular Surgery, 119, 515-524. http://dx.doi.org/10.1016/S0022-5223(00)70131-0

[17] Hammon Jr., J.W., Graham Jr., T.P., Boucek Jr., T.J., Parish, M.D., Merril, W.H. and Bender Jr., H.W. (1987) Myocardial Adenosine Triphosphate Content as a Measure of Metabolic and Functional Myocardial Protection in Children Undergoing Cardiac Operation. The Annals of Thoracic Surgery, 44, 467-470. http://dx.doi.org/10.1016/S0003-4975(10)62103-0

[18] Kuruvilla, S., Balakrishnan, K.R. and Parvathy, U. (2004) Right Ventricular Myocardium in Fallot's Tetralogy: A Light Microscopic, Morphometric and Ultrastructural Study. Images in Paediatric Cardiology, 21, 1-30.

[19] de Lorgeril, M., Friedli, B. and Assimacopoulos, A. (1984) Factors Affecting Left Ventricular Function after Correction of Tetralogy of Fallots. British Heart Journal, 52, 536-541. http://dx.doi.org/10.1136/hrt.52.5.536

[20] Cobanoglu, A. and Schultz, J.M. (2002) Total Correction of Tetralogy of Fallot in the First Year of Life: Late Results. The Annals of Thoracic Surgery, 74, 133-138. http://dx.doi.org/10.1016/S0003-4975(02)03619-6

[21] Del Nido, P.J., Mickle, D.A., Wilson, G.J., Benson, L.N., Coles, J.G., Trusler, G.A. and Williams, W.G. (1987) Evidence of Myocardial Free Radical Injury during Elective Repair of Tetralogy of Fallot. Circulation, 76, 174-179.

[22] Chaturvedi, R.R., Shore, D.F., Lincoln, C., Mumby, S., Kemp, M., Brierly, J., et al. (1999) Acute Right Ventricular Physiology after Repair of Tetralogy of Fallot. Circulation, 100, 1540-1547. http://dx.doi.org/10.1161/01.CIR.100.14.1540

[23] Fleck, A. and Myers, M. (1995) Cellular Aspects of Clinical Biochemistry. In: Marshall, W.J. and Bangert, S.K., Eds., Clinical Biochemistry, Churchill Livingstone, New York, 717-738.

[24] Chevion, M., Jiang, Y., Har-El, R., Berenshtein, E., Uretzky, G. and Kitrossky, N. (1990) Copper and Iron Are Mobilized Following Myocardial Ischemia: Possible Predictive Criteria for Tissue Injury. Proceedings of the National Academy of Sciences of the United States of America, 90, 1102-1106. http://dx.doi.org/10.1111/j.1600-0609.1987.tb01425.x

[25] Konijn, A.M. and Hershko, C. (1977) Ferritin Synthesis in Inflammation. I. Pathogenesis of Impaired Iron Release. British Journal of Haematology, 37, 7-16.

[26] Zdravkovic, D. (1987) Changes in Serum Ferritin Following Surgical Trauma. European Journal of Haematology, 38, 60-62. http://dx.doi.org/10.1111/j.1600-0609.1987.tb01425.x

[27] Higgins, C.B. (1992) What Standard Has the Gold? Journal of the American College of Cardiology, 19, $1608-1609$. http://dx.doi.org/10.1016/0735-1097(92)90626-X

[28] Gatzoulis, M.A., Clark, A., Cullen, S., Newman, C.G. and Redington, A.N. (1995) Right Ventricular Diastolic Dysfunction 15 - 35 Years after Repair of TOF: Restrictive Physiology Predict Superior Exercise Performance. Circulation, 91, 1775-1781. http://dx.doi.org/10.1161/01.CIR.91.6.1775

[29] Denault, A.Y., Couture, P., Buithieu, J., Haddad, F., Carrier, M., Babin, D., Levesque, S. and Tardif, J.C. (2006) Left and Right Ventricular Diastolic Dysfunction as Predictors of Difficult Separation from Cardiopulmonary Bypass. Canadian Journal of Anesthesia, 53, 1020-1029. http://dx.doi.org/10.1007/BF03022532

[30] Hsu, D.T. and Pearson, G.D. (2009) Heart Failure in Children: Part I: History, Etiology, and Pathophysiology. Circulation: Heart Failure, 2, 63-70. http://dx.doi.org/10.1161/CIRCHEARTFAILURE.108.820217 
Scientific Research Publishing (SCIRP) is one of the largest Open Access journal publishers. It is currently publishing more than 200 open access, online, peer-reviewed journals covering a wide range of academic disciplines. SCIRP serves the worldwide academic communities and contributes to the progress and application of science with its publication.

Other selected journals from SCIRP are listed as below. Submit your manuscript to us via either submit@scirp.org or Online Submission Portal.
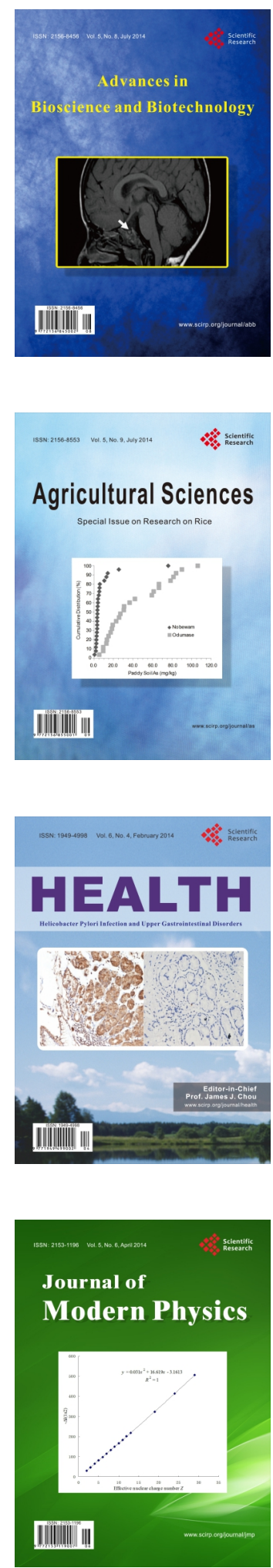
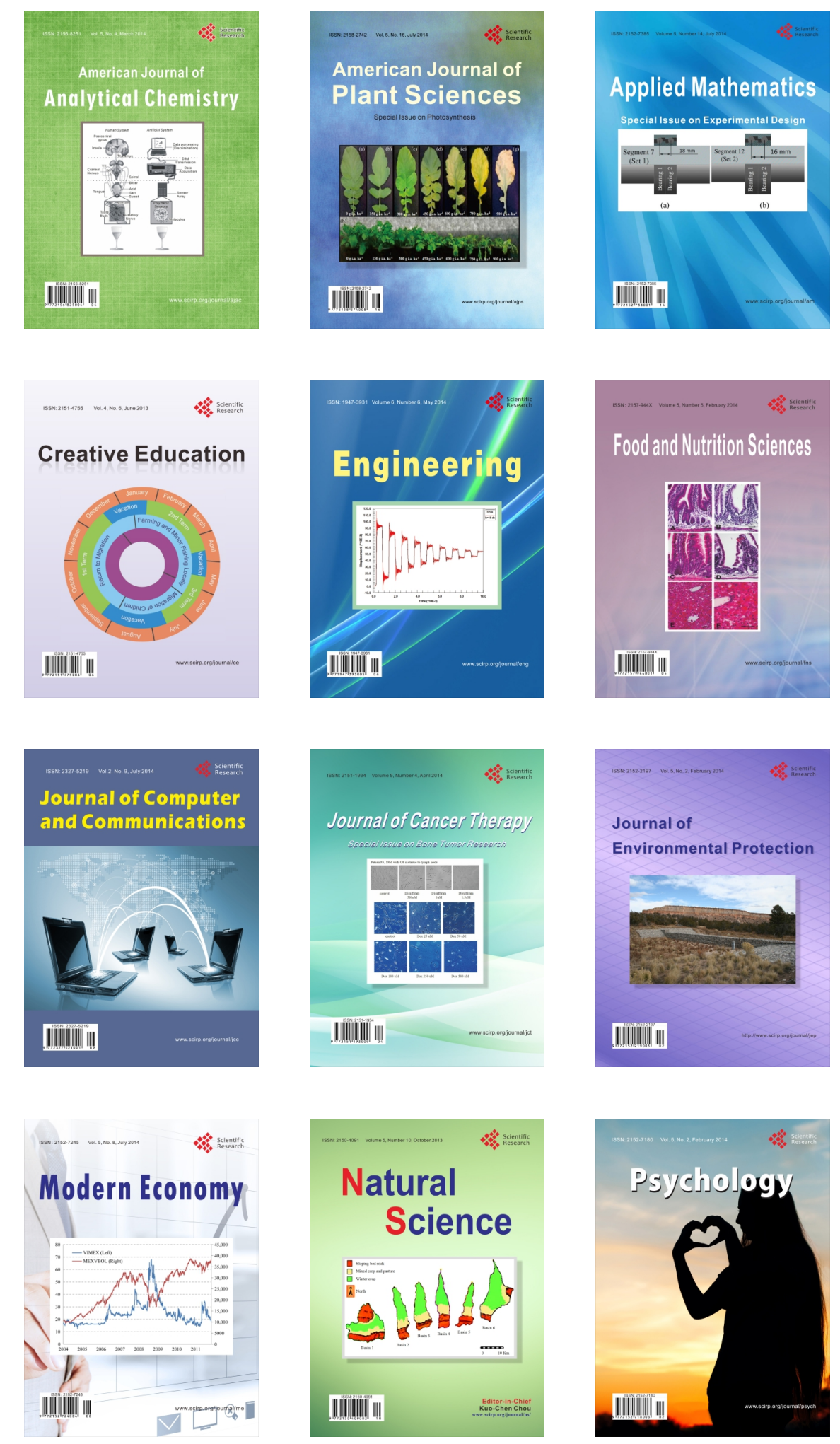